\title{
Improvement of the "Law of 60 Days" by Implementing Patient Navigation Within the Breast Cancer Program: Pilot Project in Rio De Janeiro
}

\section{Maria Luisa Marsillac ${ }^{1,2 *}$, Sandra Gioia ${ }^{2,3,5}$, Fernanda Campos da Silva $^{1}$, Cristiane Torres ${ }^{2}$, Lucia Brigadão², Sandra San Miguel ${ }^{4}$, Alexandra Bukowski ${ }^{5}$, Lindsay Krush ${ }^{5}$ and Paul E Goss ${ }^{5}$}

${ }^{1}$ Federal University of the State of Rio de Janeiro(UNIRIO), Rio de Janeiro, Brazil

${ }^{2}$ State Secretary of Health, Rio De Janeiro, Brazil

${ }^{3}$ Brazilian National Cancer Institute (INCA), Rio De Janeiro, Brazil

${ }^{4}$ National Cancer Institute, Rockville, Maryland, USA

${ }^{5}$ Global Cancer Institute, Massachusetts General Hospital Cancer Center, Harvard

Medical School, Boston, Massachusetts, USA

*Corresponding Author: Maria Luisa Marsillac, MD; PPGMED/DECIGE.

University Hospital Gaffrée e Guinle(HUGG) - UNIRIO, $2^{\circ}$ Floor. Rua Mariz e

Barros, 775 - Rio de Janeiro, RJ, Brazil. E-mail: malumarsillac@gmail.com

DOI: 10.31080/ASCB.2020.04.0203
Received: January 17, 2020

Published: January 28, 2020

(C) All rights are reserved by Maria Luisa

Marsillac., et al.

\begin{abstract}
Background: Patient Navigation Program (PNP) assists patients to reduce delays in diagnosis and treatment. A study was conducted on how PNP in Rio de Janeiro, Brazil, could promote adherence to the "Law of 60 Days", which states that all patients with cancer within the public system should start treatment within 60 days after diagnosis of cancer.

Materials and Methods: From August 2017 to May 2018, 105 patients aged 33-80 years (mean 59 years) were recruited for Patient Navigator. Follow-up was by phone, email, or text message. PNP implemented at Rio Imagem was designed to: 1) collect important data on specific barriers, and 2 ) ensure that at least $70 \%$ of the patients recruited with breast cancer initiate treatment within the mandatory 60-days period.

Results: Patients presented with stage 0 (4\%), I-IIA (38\%), IIB-IIIB (48\%) and IV (5\%). These included barriers to compliance with the law: fear and fatalistic thoughts (99\%), financial burden (79\%), uncoordinated health care (76\%), attitudes towards providers (75\%), duplicity of pre-treatment exams (52\%), patient-provider communication (52\%), transport (42\%), scheduling (24\%), and queues for surgical treatment (12\%). PNP had $100 \%$ patient satisfaction and in $52 \%$ of the cases it helped the patients to start treatment within the period established by law.

Conclusion: PNP in Rio did not reach the success rate a 70\% to comply with the law, as intended (it reached 52\%). However, the barriers that PN did not manage to overcome the lack of human resources and medical supplies, were informed to the health authorities and to the hospital managers.
\end{abstract}

Keywords: Patient Navigation; Breast Neoplasms; Barriers; Health Systems

\section{Introduction}

By 2025 , estimates suggest that $50 \%$ of the new cancer cases and $60 \%$ of cancer-related deaths may occur in developing countries [1]. In countries such as the United States of America (USA), the United Kingdom, France, and Australia, there was a decline in mortality in the past two decades, while in Latin America (LA), an increase in mortality related to cancer was seen in the same period. In general, the survival rates in LA countries are for all cancers 
on average, $30 \%$ below that of European countries or the USA [2]. Among cancer cases, breast cancer is a major public health problem worldwide. In 2016, it was the second most prevalent cancer, with about 2 million new cases and approximately 626,000 deaths worldwide [3].

In Brazil, breast cancer is the most common type of cancer and the leading cause of cancer-related death among women. In 2015, 15,403 cancer-related deaths were registered in the country, and 59,700 new cases were estimated for 2018 [4,5]. Many patients faced delays in diagnosis and treatment due to barriers to accessing cancer treatment in the country subsequently leading to higher mortality rates. In LA countries long delays often lead to progression of cancer and clinical upstaging. In the USA, $60 \%$ of the cases of breast cancer are diagnosed in the early stage of the disease, while in Brazil this is true for only $20 \%$ of those diagnosed [6].

In 2012, the Brazilian government recognized delays in diagnosis and treatment as an issue and decreed Law No. 12.732/12 of the Ministry of Health, or the "Law of 60 Days". This law establishes that patients who use the public health system should be treated for any type of cancer within 60 days after diagnosis [7]. However, even years after the law's implementation, a considerable number of patients still do not receive treatment in a timely manner and innovative solutions are necessary to guarantee that the law be properly implemented. Data collected in 239 hospitals throughout Brazil showed that almost $40 \%$ of the patients with breast cancer were not able to begin treatment within the 60 day period [8]. Data from the Ministry of Health show that in Rio de Janeiro the problem is even more prominent, with more than $90 \%$ of women not starting treatment within the mandatory 60 day deadline [9].

In this context, patient navigation program (PNP) can make a significant difference. Patient navigation is "a coordinated process of individualized assistance offered to patients to overcome barriers to accessing quality care and treatment in a timely manner". PNP has been successful among the poor population in the USA, but its global implementation has proven to be limited [10]. PNP has the potential to reduce the barriers of the health system and support the respect to the "Law of 60 Days" in Brazil [11].

In this pilot study, PNP implemented in Rio de Janeiro was designed to: 1) collect important data on specific barriers of women with breast cancer in Rio de Janeiro, and 2) to ensure that at least
$70 \%$ of the patients recruited with breast cancer initiate treatment within 60 days of histopathological diagnosis.

\section{Material and Methods}

Study site

Patients were recruited to receive PNP intervention at the State Center for Diagnosis and Imaging, known as Rio Imagem, in Rio de Janeiro City. At this Diagnostic Center, approximately 4,000 mammograms and 120 breast biopsies are performed each month by women from 92 municipalities of the state of Rio de Janeiro and users of the Unified Health System (SUS). The results of the biopsies performed at Rio Imagem are delivered directly to patients within 30 days. However, there is no supervision to determine whether the patient with a positive result for malignancy ( $40 \%$ of the biopsies) has been properly referred for treatment. PN was introduced in this setting to refer patients to the appropriate center for initiation of treatment using the existing network of treatment centers. Our study was approved by the Institutional Review Board (IRB) of the Brazilian National Cancer Institute.

\section{Patient navigator}

A social worker experienced in breast cancer patients and trained to be a patient navigator (PN) was responsible for guiding the patient through the health system. PN was aware of the functioning of the State System of Regulation (SER) of Rio de Janeiro, which determines to which hospital the patient will be referred to begin treatment. Responsibilities of PN included: to help patients fill out insurance documents; to guide patients toward timely treatment; to identify local resources and support, children aid resources, etc.; to help patients attend appointments at Rio Imagem; to remind patients about future appointments; to facilitate communication between patients and healthcare providers; to certify that the information provided to the patient is clearly understood and help to answer any question regarding follow-up; and to explain the end of the PN to the patient.

Consecutive patients seen at Rio Imagem over a 10-month period who fulfilled inclusion criteria were invited to participate. After signing appropriate informed consent, information on the existence of perceived barriers to access to health was obtained from the main questionnaire and the psychosocial interview. Data were collected on dates and references to clinical information, PN workflow, patient satisfaction, and more detailed information about the patient's disease and difficulties. 
PN contacted the patient at least once a week by phone, email, or text message. PN ended for a patient once she began her first breast cancer treatment course. A patient was considered "lost to follow-up" in the study after the PN had tried to make 3 calls, had sent a written letter, and had made 3 additional calls ( 1 call per week after the letter had been sent).

\section{Population of patients}

The inclusion criteria for the study were female patients over 18 years old and users of the SUS. The exclusion criteria were: unable to provide necessary personal documents; patients with private health insurance; patients that only need supportive care (survival prognosis of less than 6 months); terminally ill patients due to another disease (survival prognosis of less than 6 months); unsheltered people; history of sexual abuse or alcoholism; patients that suffer major psychotic disorders or uncontrolled psychiatric disorders; mentally impaired patients; imprisoned patients.

\section{Sample size and statistical analysis}

This study aimed to enroll at least 100 patients in the PNP. The sample was calculated based on at least $70 \%$ of the patients with breast cancer beginning treatment in the period of 60 days. A past study on Rio de Janeiro ${ }^{9}$ showed that only $30 \%$ of the women with breast cancer begin treatment within 60 days. Therefore, the hope was to improve this number by $40 \%$, to achieve a success criterion of $70 \%$ or more. Finding a difference of $40 \%$ required that 100 patients are needed to achieve a statistical power of $80 \%$ and a significance level of 0.05 .

For descriptive analysis, quantitative variables are presented as mean and standard deviation, while the qualitative variables are presented by their absolute and relative frequencies.

\section{Results}

A total of 105 patients signed consent and were enrolled between August 2017 and May 2018. Eight patients were excluded because of lost to follow-up. There were two deaths related to breast cancer in our study. Median age was 59 years (range 3380). All patients were female, lived in urban areas and spoke only Portuguese. Main sociodemographic and clinical characteristics data of the patients are shown in (Table 1 and Table 2).

One hundred percent of the patients were satisfied with their PN work. This measurement was obtained through the patient satisfaction questionnaire to assess the patient's experience throughout the navigation process and their satisfaction with the NP relationship and services.

Fifty two percent of cases it helped to start treatment within the deadline established by the law. No patients with stage 0 and only $13 \%$ with stage I-IIA started the treatment within 60 days; mean time from diagnosis to treatment was 110 days (range 9-287). Thirty-eight percent of patients with stage IIB-IV complied with the law, mean time 31 days (range 1-58). Figure 1 shows the proportion of patients $(n=97)$ treated according to the time to start treatment and staging.

\begin{tabular}{|c|c|}
\hline $\begin{array}{l}\text { Sociodemographic characteristics } \\
\text { data }\end{array}$ & $\begin{array}{l}\text { All patients } \\
(\mathrm{N}=105)\end{array}$ \\
\hline Median age, years (range) & $59(33-80)$ \\
\hline$<50$ & $24(23 \%)$ \\
\hline$\geq 50$ & $81(77 \%)$ \\
\hline \multicolumn{2}{|l|}{ Time to get to Rio Imagem } \\
\hline$<1$ hour & $43(41 \%)$ \\
\hline Between 1 hour and $<2$ hours & $40(38 \%)$ \\
\hline 2 hours and $<6$ hours & $21(20 \%)$ \\
\hline 6 hours and $<12$ hours & $1(1 \%)$ \\
\hline \multicolumn{2}{|l|}{ Means of transport } \\
\hline Public & $96(91,4 \%)$ \\
\hline Patient's own & $9(8,6 \%)$ \\
\hline \multicolumn{2}{|l|}{ Education Level } \\
\hline Elementary school & $68(65 \%)$ \\
\hline Middle school & $28(27 \%)$ \\
\hline High school & $9(8 \%)$ \\
\hline \multicolumn{2}{|l|}{ Marital status } \\
\hline Married & $41(39 \%)$ \\
\hline Single & $28(27 \%)$ \\
\hline Widow & $20(19 \%)$ \\
\hline Separated / divorced & $16(15 \%)$ \\
\hline \multicolumn{2}{|l|}{ Number of children } \\
\hline none & $10(9,5 \%)$ \\
\hline Up to 3 children & $83(79 \%)$ \\
\hline 4 to 6 children & $10(9,5 \%)$ \\
\hline 7 to 10 children & $2(2 \%)$ \\
\hline \multicolumn{2}{|l|}{ Number of people living with the patient } \\
\hline None & $14(13 \%)$ \\
\hline Up to 3 people & $64(61 \%)$ \\
\hline From 4 to 6 people & $24(23 \%)$ \\
\hline From 7 to 9 people & $3(3 \%)$ \\
\hline \multicolumn{2}{|l|}{$\begin{array}{l}\text { The cost of the people at the residence } \\
\text { dependants on the patient's income }\end{array}$} \\
\hline Yes & $29(27,6 \%)$ \\
\hline No & $76(72,4)$ \\
\hline \multicolumn{2}{|l|}{ Total household income } \\
\hline$<1$ minimum wage * & $41(39 \%)$ \\
\hline From 1 to 2 minimum wages & $15(14 \%)$ \\
\hline$>2$ minimum wages & $49(47 \%)$ \\
\hline \multicolumn{2}{|l|}{ Has own cell phone } \\
\hline Yes & $100(95 \%)$ \\
\hline No & $5(5 \%)$ \\
\hline \multicolumn{2}{|l|}{ Has a computer } \\
\hline Yes & $48(50 \%)$ \\
\hline No & $52(50 \%)$ \\
\hline
\end{tabular}

Table 1: Main sociodemographic characteristics data of the patients $(\mathrm{N}=105)$ *minimum wage $(<\$ 251 \mathrm{USD} /$ month) 12 . 


\begin{tabular}{|l|c|}
\hline Clinical Characteristics Data & All Patients (N 105) \\
\hline $\begin{array}{l}\text { Mean time between mammography } \\
\text { and biopsy, days (range) }\end{array}$ & $67(2-371)$ \\
\hline $\begin{array}{l}\text { Mean time between biopsy and first } \\
\text { time referral hospital, days (range) }\end{array}$ & $30(1-73)$ \\
\hline Mean time between histopathologi- & $79(1-287)$ \\
cal report and start treatment, days & \\
(range) & \\
\hline Clinical staging & \\
in situ & $4(4 \%)$ \\
I & $13(12 \%)$ \\
IIA & $27(26 \%)$ \\
IIB & $9(8,5 \%)$ \\
IIIA & $10(9,5 \%)$ \\
IIIB & $31(30 \%)$ \\
IV & $5(5 \%)$ \\
no data & $6(5 \%)$ \\
\hline Histological type & \\
IDC & $96(91 \%)$ \\
ICL & $5(5 \%)$ \\
DCIS & $4(4 \%)$ \\
\hline Histological grade & $13(12,5 \%)$ \\
I & $63(60 \%)$ \\
II & $20(19 \%)$ \\
III & $9(8,5 \%)$ \\
not applicable & $28(27 \%)$ \\
\hline Biological profile & $39(37 \%)$ \\
Luminal A & $6(6 \%)$ \\
Luminal B & $14(13 \%)$ \\
HER2 positive & $18(17 \%)$ \\
Triple negative & \\
no date & \\
\hline Related deaths & \\
\hline
\end{tabular}

Table 2: Main clinical characteristics data of the patients $(\mathrm{N}=105)$.

All patients reported at least one barrier, (ranging from 2 to 12 barriers). Figure 2 shows the main barriers to comply with the law.

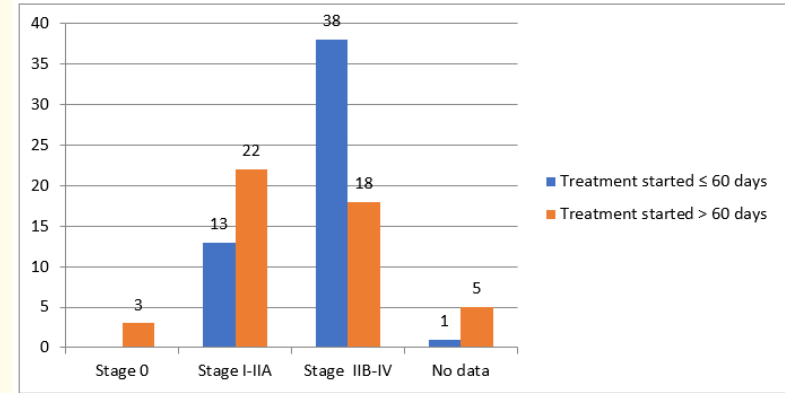

Figure 1: Proportion of patients according to the time to start treatment and staging (\%).

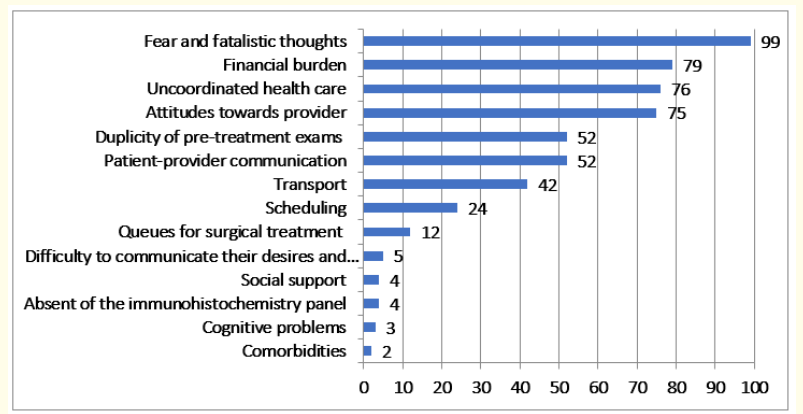

Figure 1: Proportion of patients reporting each barrier (\%).

\section{Discussion}

Approaches focused on specific populations and with integral information allow the decision makers to understand the needs of each group and plan specific actions to improve the quality of the services provided [13].

The use of the PN facilitates the appropriate and efficient use of services. It is a program that is considered an indicator of quality in several health services in the USA, Canada, and Europe. PN is a link between the patient and the system, the health professionals, and providers, which brings equity to the vulnerable population [11,14-15]. 
PNs are trained health care providers who facilitate the process within the health system, helping patients to overcome institutional, socioeconomic, and personal barriers to cancer care access. They provide services such as scheduling diagnostic and followup appointments. Additionally, PNs coordinate the communication between patients and health care providers. PNs help patients receive medical care in a timely manner and reduce the delays in care and decrease lost to follow-up rates [11].

Although Brazil has made improvements regarding breast cancer prevention and control, the country continues to face high breast cancer incidence, late-stage diagnosis, and high mortality rates. In Brazil, breast malignancies are highly incident and are the main cause of cancer-related deaths among women. Barriers to accessing healthcare lead to delays in the diagnosis and treatment and ultimately lead to advanced stage disease presentation and high mortality [14].

In this study, all patients were satisfied with PN work and performance. The patients felt safe with the guidance of PN about the next steps in the health system. All patient doubts were addressed, offering a positive experience in SUS. One patient stated, "I feel like I'm in a first-world country with this service." This last statement reminds us that this project started in the USA to provide care to patients that had difficulty in reaching the breast cancer care and reached an extraordinary result of elevating the survival rate from $31 \%$ to $70 \%$ in the 1990 s. This accomplishment has led PN to be recognized by the American Government since 2005 [6].

Educational, emotional and cultural barriers can be very well addressed by the PN [15]. PN has helped break down these barriers by explaining the health system, educating patients about diagnosis and medical procedures, highlighting the importance of attending appointments and examinations, providing more details about treating the disease, consulting with psychological support groups and informing patient that she is not alone in this process.

Regarding health system barriers, PN was fundamental in some cases, such as avoiding duplication of pretreatment tests or making direct contact with Family Health Centers to guide their insertion in the SER. Without this step, the patient cannot be treated at the referral hospital. PN instructed the patients to perform the tests necessary to reach the full staging referral centers. This is ex- tremely important for optimizing time and resources [15]. When surgical treatment was suggested, the role of PN was affected by the lack of human resources to perform preoperative clinical evaluations and surgical procedures.

In fact, patients with an initial clinical stage had difficulty obtaining surgical treatment. No patient with an in situ stage and only $13 \%$ with stage I-IIA started the treatment in 60 days. Data from the Ministry of Health [9], from 2013 to 2017, corroborate the findings of this study. In Rio de Janeiro, patients diagnosed in a health diagnosis center and in an initial stage comply with the law in 5.8\% (mean of 164 days), while advanced patients comply it in $15.6 \%$ (mean of 129 days). The rate of compliance with the law in Brazil is, on average, $36 \%$ at initial stage (mean of 135 days) and $49 \%$ at an advanced stage (mean of 113 days).

According to a report on the National Policy on Cancer Care [16], reference units in Rio de Janeiro account for only $29 \%$ of the surgical demand. This suggests to the managers of the Ministry of Health the expansion of the offer of services, either by means of own investments or by the contracting of supplementary services, until the complete solution of the existent deficiencies, especially, in relation to the offer of oncological surgeries.

In this study, the most common barriers were fear and financial burden, which are also reported by Latinos with cancer in the US [17]. Knowing the barriers to health care allowed PN to focus on solutions to these barriers. PN educated patients about medical diagnoses and procedures and provided more details about the treatment of the disease, reducing the barriers to the initiation of treatment. This shows the importance of PN in the Brazilian context, which presents a population prone to low adherence to recommendations for early detection by socioeconomic and cultural factors [18].

PNP has shown us that navigation is an innovative solution to a complex problem in Brazil [14]. PNP is designed to eliminate barriers and bureaucracies with special attention to the patient and not the disease itself. The reallocation of the budget focused on the use of scarce resources can result in prevention and early treatment of breast cancer. In the Brazilian context, the PNP can represent an opportunity to have a great potential of integration in the federal, state and, municipal health systems [11]. 
The main limitation of our study is the lack of a control arm. However, PN was responsible for the compliance of the "Law of 60 Days" in $52 \%$ of the cases. Currently, data from the Ministry of Health show that only $10 \%$ of patients who were diagnosed in a health diagnosis center in Rio de Janeiro are in compliance with this law [9]. The study showed the feasibility of PN within a health system fragmented in a LA and with possibilities of new studies comparing PN with the standard care.

\section{Conclusion}

PNP in Rio did not reach the success rate a 70\% to comply with the law, as intended (it reached 52\%). However, the barriers that PN did not manage to overcome such as the lack of human resources and medical supplies, were informed to the health authorities and to the hospital managers.

\section{Acknowledgements}

Lirio Cipriani, Avon Institute; Luiz Antonio Teixeira Junior, State Secretariat of Health Rio de Janeiro; Claudia Dutra, Gnosis Institute; Marcelle Medeiros, Fundação Laço Rosa; Eduardo Millen, Brazilian Society of Mastology.

Supported by The Global Cancer Institute (Boston, MA) and Avon International Breast Cancer Research Program, Massachusetts General Hospital (Boston, MA).

\section{Bibliography}

1. Bray F., et al. "Global estimates of cancer prevalence for 27 sites in the adult population in 2008". International Journal of Cancer 132.5 (2013):1133-1145.

2. Goss PE., et al. "Planning cancer control in Latin America and the Caribbean". The Lancet Oncology 14 (2013): 391-436.

3. Bray F., et al. "Global Cancer Statistics 2018: GLOBOCAN Estimates of Incidence and Mortality Worldwide for 36 Cancers in 185 Countries". CA: A Cancer Journal for Clinicians 0 (2018): 1-31.

4. Instituto Nacional de Câncer (Brasil): Estatísticas do câncer: Mortalidade (2018). http://www1.inca.gov.br/vigilância/ mortalidade.asp. Accessed June 11, 2018.

5. Instituto Nacional de Câncer (Brasil): Estimativa 2018: Incidência de câncer no (2018). http://www.inca.gov.br/estimativa/2018/sintese-de-resultados-comentarios.asp. Accessed June 11, 2018.

6. Unger-Saldãna K. "Challenges to the early diagnosis and treatment of breast cancer in developing countries". World Journal of Clinical Oncology 5 (2014): 465-477.

7. Presidência da República: Lei (2012):12.732. http://www. planalto.gov.br/ccivil_03/_ato2011-2014/2012/lei/112732. htm.

8. Federação Brasileira de Instituições Filantrópicas de Apoio a Saúde da Mama: Pesquisa: A implementação da Lei dos 60 dias (2018). http://www.femama.org.br/novo/arquivos/audiencia_publica_pesquisa_60_dias.pdf
9. Ministério da Saúde. "Relatório de Intervalo de Tempo". Integrador RHC (2018). https://irhc.inca.gov.br/RHCNet/jasper/ pdf on 04/22/2019. Accessed June 11, 2018.

10. Bukowski A., et al. "The potential role of patient navigation in low- and middle-income countries for patients with cancer". JAMA Oncology 2 (2016): 994-995.

11. Bukowski A., et al. "Patient Navigation to Improve Access to Breast Cancer Care in Brazil". Journal of Global Oncology 5 (2017): 433-437.

12. Valor do salário mínimo e a sua política de valorização de longo (2019). http://www.in.gov.br/materia/-/asset_publisher/ Kujrw0TZC2Mb/content/id/57510734/do1esp-2019-0101-decreto-n-9-661-de-1-de-janeiro-de-2019-57510684. Accessed May 11, 2019.

13. Harford J., et al. "Guideline Implementation for Breast Healthcare in Low- and Middle-Income Countries". CANCER Supplement 15.113 (2008): 2282-2296.

14. Gioia S. "Why is breast cancer early detection important?" Mastology 27.3 (2017):173-175.

15. Naomi Ko., et al. "Can Patient Navigation Improve Receipt of Recommended Breast Cancer Care? Evidence from the National Patient Navigation Research Program". Journal of Clinical Oncology 32 (2014): 2758-2764.

16. Relatório de auditoria operacional do Tribunal de Contas da União. Política Nacional de Atenção Oncológica. Brasília: TCU, Secretaria de Fiscalização e Avaliação de Programas de Governo (2011). https://portal.tcu.gov.br/lumis/portal/file/fileDownload.jsp?inline=1\&fileId=8A8182A14D6E85DD014D73 27C1CB5497. Accessed June 11, 2018.

17. Tejeda S., et al. "Patient barriers to follow-up care for breast and cervical cancer abnormalities". Journal of Women's Health (Larchmt) 22 (2013): 507-517.

18. Ohl ICB., et al. "Public actions for control of breast cancer in Brazil: integrative review". Revista Brasileira de Enfermagem 69.4 (2016): 746-755.

\section{Assets from publication with us}

- Prompt Acknowledgement after receiving the article

- Thorough Double blinded peer review

- Rapid Publication

- Issue of Publication Certificate

- High visibility of your Published work

Website: https://www.actascientific.com/

Submit Article: https://www.actascientific.com/submission.php Email us: editor@actascientific.com

Contact uS: +919182824667 